REVISTA DE DERECHO UNED, NÚM. 9, 2011

\title{
LA SEGUNDA INSTANCIA CIVIL TRAS LA ENTRADA EN VIGOR DE LA LEY 37/2011, DE 10 DE OCTUBRE, DE MEDIDAS DE AGILIZACIÓN PROCESAL
}

\author{
Salvador Iglesias Machado \\ Doctor en Derecho, Letrado del Consejo Consultivo de Canarias, \\ Profesor-tutor de la UNED
}

Resumen: La nueva Ley 37/2011, de 10 de octubre, opera importantes modificaciones en la LEC-2000, tanto en su parte general como en la especial. El trabajo que presentamos se limita a analizar exclusivamente aquellos aspectos de la reforma que inciden en el recurso de apelación civil, que ahora se ve modificado en cuanto a las resoluciones recurribles y en cuanto al procedimiento. La nueva Ley justifica las medidas, que denomina de «agilización procesal», en el uso abusivo de la segunda instancia y en la necesidad de suprimir trámites innecesarios. Un destacado sector de la doctrina científica se ha mostrado crítico con la Ley al considerar que la limitación del recurso de apelación en los juicios verbales por razón de la cuantía es contraria al principio de igualdad que consagra el artículo 14 de la $\mathrm{CE}$. Se considera que el derecho a los recursos en materia civil debe encuadrarse en el derecho constitucional a un proceso con todas las garantías, más que en el derecho a la tutela judicial efectiva.

Palabras clave: Apelación civil, resoluciones recurribles y procedimiento, Constitución Española.

Abstract: The new 37/2011 Law, dated 30th October, brings about important modifications to the LEC-2000, to both its general and special parts. The paper we are presenting is restricted exclusively to analyze those aspects of the reform which impinge upon civil appeals, 
now modified with regards to appealable decisions and procedures. The new law justifies those measures referred to as "procedural expedition» on the excessive use of the second instance and in the need to remove unnecessary formalities. A prominent sector of scientific opinion has been critical of the law, in the belief that limiting the right of appeal in verbal court cases on the grounds of quantity is contrary to the principle of equality established under Article 14 of the Spanish Constitution. It considered the rights of appeal in civil matters should be classified under the constitutional right to fully guaranteed proceedings rather than on the right to judicial protection.

Key words: Civil Appeal, Decisions subject to appeal and proceedings, The Spanish Constitution.

Sumario: I. Introducción.-II. La nueva regulación de la apelación civil, resoluciones recurribles y procedimiento.-III. Conclusiones.

\section{INTRODUCCIÓN}

La Ley 37/2011, de 10 de octubre, de Medidas de Agilización Procesal, con fecha de entrada en vigor el 31 de octubre de 2011, incorpora determinadas medidas de agilización en los órdenes jurisdiccionales civil, penal y contencioso-administrativo, modificando las Leyes de Enjuiciamiento Civil (Ley 1/2000, de 7 de enero, citada en adelante como LEC-2000), de Enjuiciamiento Criminal (Ley de 14 de septiembre de 1882), Reguladora de la Jurisdicción Contenciosa-Administrativa (Ley 29/1998, de 13 de julio) y la de Venta a Plazos de Bienes Muebles (Ley 28/1998, de 13 de julio), aunque el eje central de la reforma gira en torno al procedimiento civil. A su análisis nos dedicaremos en estas líneas aunque centrándonos exclusivamente en el recurso de apelación civil.

La modificación de la LEC-2000 por la Ley 37/2011, de 10 de octubre, de Medidas de Agilización Procesal ${ }^{1}$, comporta una amplia reforma procesal que afecta tanto a la parte general como a la especial, aunque en distinta medida. La norma tiene por objeto, según afirma su Preámbulo, introducir en la legislación procesal mejoras que permitan agilizar los distintos procedimientos sin merma de las garantías

${ }^{1}$ Es una de las últimas leyes aprobadas en la IX legislatura. Publicada en el BOE de 11 de octubre de 2011, núm. 245 [págs. 106726 y ss.]. 
para el justiciable. Previamente, justifica la medida anunciando que los datos estadísticos más recientes sobre la entrada de asuntos en los órganos judiciales, han experimentado en los últimos tiempos una subida exponencial de la litigiosidad, hecho que el legislador atribuye a la cada vez mayor confianza de los ciudadanos en la Administración de Justicia, afirmación que no parece guardar relación con los resultados de las estadísticas publicadas sobre la materia².

\section{LA NUEVA REGULACIÓN DE LA APELACIÓN CIVIL, RESOLUCIONES RECURRIBLES Y PROCEDIMIENTO}

El objeto de la Ley es introducir determinadas medidas que denomina de «agilización procesal» en los tres órdenes jurisdiccionales citados; aunque el trabajo que presentamos se limita exclusivamente a aquellas que afectan al orden jurisdiccional civil y, más particularmente, al recurso de apelación civil. Algunas de las medidas pretenden suprimir, en palabras del legislador, trámites procesales innecesarios o sustituirlos por otros más breves, mientras que, otras medidas, están encaminadas a limitar el «uso abusivo» de instancias judiciales.

La reforma afecta a la parte general de la Ley de Enjuiciamiento Civil en lo relativo a: actos de comunicación, comunicaciones en domicilio y comunicaciones por medios técnicos, efectos económicos del proceso y gastos del proceso; y también a su parte especial: proceso de declaración, procesos verbales con especialidades: A) proceso de desahucio, $1^{\circ}$. Enervación del desahucio, $2^{\circ}$. Juicio de desahucio y especialidades del desahucio por falta de pago de rentas o cantidades debidas. Nuevo juicio monitorio de desahucio. B) Nuevo proceso verbal sumario por incumplimiento de contrato de arrendamiento de bienes muebles, Procesos especiales. Procedimiento monitorio: Recursos, A) Recurso de apelación frente a sentencias, a) Resoluciones recurribles, b) Procedimiento; B) Recurso extraordinario por infracción procesal C) Recurso de casación, a) resoluciones recurribles, b) Procedimiento, D) Recurso de queja; E) Recursos en determinados procesos. Proceso de ejecución, Ejecución provisional, Ejecución dineraria, A) Ejecución dineraria en casos de bienes especialmente hi potecados o pignorados, B) Tercerías de dominio y de mejor derecho, C) Realización forzosa. Subastas ${ }^{3}$.

2 Vid. Estadísticas CGPJ, 2010, 2011, en WWW.poderjudicial.es.

3 Respecto al recurso de apelación la Ley 37/2011 afecta a los artículos 449, 457 ( $\sin$ contenido), 458, 470, 471, 473, 478, 479, 480 ( $\sin$ contenido), 481, 483.2, $1^{\circ}, 495$, 527.1 y 535.2 de la LEC-2000. 
Nos centramos aquí exclusivamente en las reformas que afectan al recurso de apelación civil y que inciden tanto en las resoluciones recurribles como en el procedimiento. Respecto a las primeras, las resoluciones recurribles, se opera una modificación importante relativa al artículo 455.1 de la LEC-2000, pues se exceptúan del recurso de apelación las sentencias dictadas en juicios verbales por razón de la cuantía cuando ésta no supere los 3.000 euros, apartándose de lo previsto inicialmente que proyectaba afectar a todos los juicios verbales seguidos por cuantía y a lo previsto en el Anteproyecto de Ley, que limitaba la apelación para los seguidos por cuantía superior a 6.000 euros. Finalmente el apartado 1 del artículo 455 queda redactado en los siguientes términos: "Las sentencias dictadas en toda clase de juicio, los autos definitivos y aquellos otros que la ley expresamente señale, serán apelables, con excepción de las sentencias dictadas en los juicios verbales por razón de la cuantía cuando ésta no supere los 3.000 euros».

El Preámbulo de la Ley justifica tal medida en la necesidad de «limitar el uso, a veces abusivo, y muchas veces innecesario, de instancias judiciales». La medida implica que un gran número de asuntos litigiosos de los ciudadanos no llegarán ahora a los órganos superiores, pues la sentencia dictada en primera instancia, en esa clase de asuntos, ganará firmeza automáticamente, quedando para el justiciable agraviado por aquélla solamente la vía de instar la declaración de error judicial, con las dificultades que ello conlleva. Ni las Audiencias Provinciales, ni mucho menos el Tribunal Supremo, podrán conocer de dichas materias en el futuro, lo que deja exclusivamente en manos del órgano a quo la resolución de esa clase de asuntos, con la consiguiente merma de las posibilidades de formación de jurisprudencia y de unificación de criterios lo cual poco favorece a la seguridad jurídica que se invoca en el Preámbulo de la Ley y que consagra el artículo 9.3 CE. Además, como no garantiza una aplicación uniforme del Derecho ante supuestos iguales, favorece la lesión del principio de Igualdad ante la Ley, consagrado en el art. $14 \mathrm{CE}$.

Desaparece, pues, el recurso de apelación en esa clase de asuntos como medio de impugnación o instrumento procesal que abre la puerta al segundo grado jurisdiccional, es decir a la doble instancia. Se pierde la posibilidad de realizar por el tribunal ad quem un segundo examen de la cuestión litigiosa, de los errores in iudicando o, por qué no, de los errores in procedendo -apelación por motivos procesales-. Así, para esa clase de asuntos, la reforma acaba con el doble grado jurisdiccional ${ }^{4}$ postulado defensor de que la cuestión de fondo sea sometida al conocimiento de un órgano jurisdiccional distinto para garantizar una reso- 
lución más justa, con mayores posibilidades de acierto; tampoco se satisface la sensación de agravio del litigante que se siente perjudicado por la sentencia del órgano unipersonal, habitualmente sobrecargado de asuntos pendientes de resolución se abandona al juez unipersonal en la función de juzgar sin que quepa luego revisar lo actuado ni corregir los posibles errores en los que haya incurrido; téngase en cuenta, en este sentido, el altísimo porcentaje de recursos de apelación que son estimados, alrededor del $40 \%$ del total de los interpuestos.

Es conocida, y no por ello necesariamente compartida, la jurisprudencia del TC que sostiene que porque al proceso civil no le son trasladables las exigencias relativas a la doble instancia, reconocidas internacionalmente ${ }^{5}$, que quedan constreñidas al proceso penal, lo que no equivale al reconocimiento generalizado al derecho a la segunda instancia, pues éste no se ampara en el artículo 24.1 de la CE. En este sentido el TC ha establecido que el establecimiento de la segunda instancia en el proceso civil carece de apoyatura constitucional y nacional (véase la STC 37/1988, de 3 de marzo, entre otras) ${ }^{6}$. Sólo una vez establecida por el legislador la segunda instancia, a través del recurso de apelación como medio de impugnación, ésta se convierte en garantía constitucional ex artículo 24.1 CE, según declara el TC. (STC 199/1998, de 25 de octubre, entre otras).

Para el TC no existe un derecho constitucional a disponer de los medios de impugnación, salvo en los procesos penales, considerando posible incluso que no existan pues ninguna norma o principio impone la necesidad de una doble instancia o de unos determinados recursos,

${ }^{4}$ Un sector de la doctrina, Prieto-Castro, Gómez de Liaño, etc., considera que sólo puede hablarse de doble grado jurisdiccional cuando se permite la incorporación de nuevas pretensiones en la segunda instancia, lo cual, según mantiene, no se cumple en los ordenamientos jurídicos que siguen el sistema de apelación limitado. Otros autores llegan incluso a sostener que sólo el sistema pleno puro cumple con el principio mencionado. Me inclino por una postura intermedia, la iniciada por Guasp: Derecho Procesal Civil, T. II, Madrid, 1977, pp. 731-732, y ahora revitalizada con matices por Saavedra: El recurso de apelación, portalderecho, www.iustel.com, p. 26.

5 Vid. Artículo 14.5 del Pacto Internacional de Derechos Civiles y Políticos, Nueva York, 1966, Instrumento de ratificación de 13-04.-1977, BOE n ${ }^{\circ} 103$, de 30 de abril de 1977 «toda persona declarada culpable de un delito tendrá derecho a que el fallo condenatorio y la pena que le haya sido impuesto sean sometidos a un tribunal superior conforme a lo prescrito en la Ley», véase también el artículo 6.1 del Convenio Europeo para la Protección de los Derechos Humanos y de las Libertades Públicas, Roma, de 4 de noviembre de 1950, Instrumento de ratificación de 26-09-1979, BOE no 143, de 10 de octubre de 1979.

6 En relación a la doctrina del TC acerca del acceso a los recursos véanse también las SSTC 3/1983, 140/1985, 106/1988, 160/19993, 294/1994, 37/1995, 58/1995, 88/1997, $71 / 2002,252 / 2004,48 / 2008$. 
lo cual corresponde establecer al legislador en el ámbito de su libertad, así lo considera en el fundamento quinto de la ya citada STC 37/1998.

Por consiguiente, según la tesis defendida por el TC, nada impide desde el punto de vista constitucional y de Derecho Internacional e incluso Comunitario, la irrecurribilidad por razón de la cuantía que afecta ahora a los juicios verbales, cuya cuantía no podrá ser inferior a 3.000 euros para que la parte que se considere agraviada por la sentencia pueda acceder al segundo grado jurisdiccional.

El Anteproyecto de Ley preveía también impedir el acceso al recurso de apelación en los procesos cuya sentencia carezca de efectos de cosa juzgada, es decir los procesos clasificados como sumarios. La cognición limitada en estos procesos es la que justifica que la sentencia no tenga efectos de cosa juzgada, quedando expedita la vía de plantear la cuestión ulteriormente, en un proceso plenario cuya sentencia sí tendría efectos de cosa juzgada. Además de las previsiones de otras leyes especiales, la LEC determina cuáles son los procesos sumarios, en los números 2 al 4 del artículo 447, por su parte los ordinales $4^{\circ}$ a $6^{\circ}, 10^{\circ}$ y $11^{\circ}$ del artículo 250.1 de la LEC complementan el anterior precepto. Las críticas de la doctrina científica, y quizás también el informe del CGPJ al texto del Anteproyecto, así como el rechazo de los operadores jurídicos, dieron paso a la definitiva redacción que, afortunadamente, omite tal desmesurada limitación.

Las restricciones en el acceso al recurso de apelación, al que aquí nos ceñimos, más que una medida de agilización procesal constituyen una merma al derecho constitucional a un proceso con todas las garantías, privando al justiciable de la posibilidad de acceso a la segunda instancia jurisdiccional por la vía de impedir el medio de impugnación por excelencia, el recurso de apelación ${ }^{7}$. Para un destacado sector de la doctrina científica, Saavedra Gallo y Pérez-Cruz Martín entre otros, los intereses en juego en cualquier clase de proceso, ya sea civil, penal, laboral o contencioso-administrativo, merecen el mismo grado de protección y precisamente para ello están los medios de impugnación en cuyo fundamento se encuentra la posibilidad de corregir los errores in iudicando o los errores in procedendo. Según Saavedra, «el derecho a los recursos no es una garantía encuadrable dentro del derecho a la tutela judicial efectiva -ahí tiene muy difícil encaje como se comprueba-, su lugar natural es el derecho a un pro2012.

7 IgLESIAS Machado: El recurso de apelación civil por cuestiones de fondo, Madrid, 
ceso con todas las garantías, porque los recursos no son más que uno de los diversos instrumentos que integran el proceso».

En realidad el objetivo de la Ley es reducir el volumen de asuntos de entrada en los tribunales, al menos en los órganos colegiados conocedores generalmente del recurso de apelación, no mejorar la tutela judicial efectiva, y para ello parte de una premisa de difícil asunción: construye la solución procesal de suprimir el recurso (de iure o de facto incrementando las cuantías). Sin embargo, la pretendida justificación, el uso abusivo del derecho a los recursos, no parece encontrar favorable acogida puesto que el abuso del derecho es cuestión singular derivada de la actuación de las partes en el caso concreto, para lo cual el ordenamiento arbitra la solución procesal adecuada. Además, en el caso de concurrir de manera generalizada el pretendido abuso del derecho a los recursos, éste se manifestaría en todos los procesos y no sólo en los juicios verbales de cuantía inferior a 3.000 euros. En realidad la medida, que consideramos regresiva, afectará al $50 \%$ de los asuntos litigiosos civiles sometidos a los tribunales. Así, la parte que se considere agraviada por la sentencia en ese tipo de asuntos se verá ahora privada del acceso a la segunda instancia, lo que no acontecerá a otros litigantes cuya pretensión supere la indicada cuantía, lo cual, como sostiene Saavedra Gallo ${ }^{8}$, «vulnera la garantía constitucional de igualdad (art. $14 \mathrm{CE}$ ) al contar unos ciudadanos con esa tutela y otros no...». En este sentido, cuando el legislador ha optado por establecer un sistema de recursos en su configuración ha de respetar el principio de igualdad, sin que quepa establecer presupuestos de admisibilidad que sean un obstáculo para su ejercicio. Así la exclusión legal que ahora comentamos, en el orden civil y limitada a la apelación, para el TC no supondría contradicción con el artículo $24.1^{9} \mathrm{CE}$, ni una vulneración del principio de igualdad del artículo $14 \mathrm{CE}^{10}$, al basarse en razones objetivas de orden procesal y no en sustantivas de exclusión.

8 SaAvedra Gallo: «La reforma de los recursos en la Ley de Medidas de Agilización Procesal», Ponencia presentada en el IV Congreso Gallego de Derecho Procesal, Congreso Internacional de Derecho Procesal.

${ }^{9}$ No hay un precedente constitucional expreso inmediato del artículo 24.1 de la CE 78, al no haber sido el precepto recogido expresamente en nuestras Constituciones, de forma implícita se encontraba en el artículo 30 de la Ley Orgánica del Estado, 1967: «todos los españoles tendrán libre acceso a los tribunales». Respecto al art. 24.2 CE 78 sus precedentes son los arts. 247 y 302 CE 1812; art. 9 CE 1837; art. 9 CE 1845; art. 11 CE 1869; art. 16 CE 1876; art. 28 CE 1931; art. 19 Fuero de los Españoles-1945.

${ }^{10}$ Los precedentes del artículo 14 de la CE de 1978 se encuentran en: art. 5 CE 1837; art. 5 CE 184; art. 27 CE 1869; art. 15 CE 2876; art. 2 CE 1931; así como en derecho comparado: art. 3 de la Constitución Italiana de 1947; art. 1 de la Constitución francesa, ex Declaración de Derechos de 26 de agosto de 1789. 
En definitiva, presupone el legislador, al final de la legislatura, que el justiciable abusa del derecho a recurrir, luego le priva del mismo para así alcanzar el tan deseado objetivo de agilización de la justicia a la vez que proclama la efectividad de la tutela judicial efectiva, lo que no deja de ser paradójico.

Empero, nos recuerda recientemente el $\mathrm{TS}^{11}$, una consolidada doctrina del TC, la cual sostiene que el derecho a una respuesta judicial sobre las pretensiones esgrimidas goza de naturaleza constitucional, ex art. 24.1 CE, mientras que el derecho a la revisión de una determinada respuesta judicial únicamente tiene carácter legal y que, como consecuencia de lo anterior, «el principio hermenéutico pro actione no opera con igual intensidad en la fase inicial del proceso, para acceder al sistema judicial, que en las sucesivas, conseguida que fue una primera respuesta judicial a la pretensión que es la sustancia medular de la tutela y su contenido esencial sin importar que sea única o múltiple, según regulen las normas procesales el sistema de recursos» ${ }^{12}$.

El tradicional modelo de apelación español, limitado, frente al paradigma del modelo francés de apelación, pleno, configurado en el Nouveau Code de Procédure Civile, (aunque creemos mejor un modelo limitado flexible que respete los nova reperta y los nova producta), ha permanecido inalterable desde sus inicios en los elementos estructurales que lo componen, consagrándose nuevamente en la LEC2000 , de relativa juventud pero que ha sido ya objeto de varias reformas, más de veinte versiones ${ }^{13}$, la última hasta el momento es la que

11 Vid. STS Sala $3^{\mathrm{a}}$, Secc. $2^{\mathrm{a}}$ de 5-1-2010.

12 Vid. SSTC 37/1995, 58/1995, 138/1995 y 149/1995, entre otras.

13 Vid. Real Decreto-ley núm. 12/2011, RCL 2011\1630; Ley 20/2011, RCL 2011\1432; Real Decreto-ley núm. 8/2011, RCL 2011\1309; Ley núm. 16/2011 de contratos de crédito al consumo, RCL 2011\1206; Ley núm. 11/2011, RCL 2011\930; Ley núm. 4/2011, RCL 2011 531; Ley núm. 13/2009, de Reforma de la Legislación Procesal para la implantación de la nueva Oficina Judicial, RCL 2009\2090; Ley núm. 54/2007, de Adopción Internacional, RCL 2007 2383; Ley núm. 41/2007, de Reforma del Mercado Hipotecario, RCL 2007 222; Ley núm. 15/2007, de Defensa de la Competencia, RCL 2007\1302; Ley Orgánica núm. 3/2007, de Igualdad, RCL 2007586; Ley núm. 19/2006, RCL 2006\1141; Ley núm. 16/2006, del Estatuto del Miembro Nacional de Eurojust, RCL 2006\1073, Ley 15/2005, RCL 2005\1471; Ley Orgánica núm. 1/2004 de Violencia de Género, RCL 200412661; Real Decreto Legislativo núm. 8/2004, sobre responsabilidad civil y seguro en la circulación de vehículos a motor, RCL 200412310; Ley núm. 60/2003 de Arbitraje, RCL 2003 3010; Ley Orgánica núm. 19/2003 de Reforma de la Ley Orgánica del Poder Judicial, RCL 2003\3008; Ley núm. 59/2003 de Firma Electrónica, RCL 2003\2975; Ley núm. 42/2003, RCL 2003\2722, en relación con la Ley 39/2002, de 28 octubre; Ley núm. 41/2003, RCL 2003\2695; Ley núm. 23/2003, de Garantías en Venta de Bienes de Consumo, RCL 2003\1764; Ley núm. 22/2003 Concursal, RCL 2003\1748; Ley núm. 39/2002, RCL 2002\2482; Real Decreto núm. 1417/2001, RCL 2001\3190. 
cierra la IX Legislatura de las Cortes Generales, y que ahora analizamos. Frente a la irrecurribilidad de las sentencias que configura la Ley 37/2011 es de prever, al impedirse el recurso de apelación y como única vía de oposición, un aumento significativo de los incidentes de nulidad del artículo 241.1 LOPJ, aunque ciertamente limitada a los motivos previstos en el precepto, tal y como acertadamente vaticina el CGPJ.

Resulta también paradójica la reforma operada, en contraste, si se me permite, con lo previsto en el Reglamento (CE) no 861/2007 del Parlamento Europeo y del Consejo, de 11 de julio de 2007, por el que se establece un proceso europeo de escasa cuantía, aplicable a litigios que no superen 2000 euros, sin incluir intereses, gastos y costas, para los que se prevé que los Estados miembros puedan establecer un recurso contra las sentencias recaídas en esos procesos de escaso importe, por contra el legislador español establece la irrecurribilidad absoluta por razón de la citada cuantía. ${ }^{14}$.

En relación con el procedimiento, se suprime el artículo 457 y se modifica el 458, relativos a los trámites iníciales del recurso de apelación. Hasta ahora el recurso principiaba con la fase de preparación mediante la presentación por el apelante, dentro del plazo de cinco días desde la notificación, del escrito de preparación en el que se limitaba a citar la resolución apelada y a manifestar su voluntad de recurrir con expresión de los pronunciamientos que impugnaba (art. 457 ahora sin contenido). La denominación de dicho trámite con el alcance descrito (cita de la resolución apelada, manifestación de la voluntad de recurrir y mención de los pronunciamientos que se recurrían) era desconocida en nuestro ordenamiento jurídico, empleaba una terminología propia del recurso de casación; y el alcance a medio camino entre la interposición y el mero anuncio del recurso, en la LEC-1881 o se anunciaba o se interponía el recurso, no cabían trámites intermedios.

La interposición directa sustituye a la fase de preparación del recurso ante el órgano a quo. El escrito de interposición se presenta también ante el mismo órgano que dictó la sentencia. La supresión del trámite de preparación resulta ahora común a todos los recursos devolutivos (apelación, infracción procesal y casación) «...por considerar -la Ley- que supone una dilación de los plazos de resolución innecesaria y que no necesariamente aporta seguridad jurídica, o ventaja alguna ni al recurrente ni a la administración de justicia».

${ }^{14}$ Vid. Informe del CGPJ al Anteproyecto de Ley de medidas de agilización procesal y concretamente el voto particular de los vocales C. Espejel Jorquera y C. Fernández-Carnicero, www.poderjudicial.es/CGPJ. 
Para articular de modo fundado la impugnación se establece un plazo de 20 días, contados a partir del siguiente al de la notificación de la resolución recurrida (artículo 458.1 LEC). En la regulación vigente hasta la reforma el plazo era de 5 días para preparar y veinte para interponer, contados desde su emplazamiento. Se acortan así los plazos en perjuicio del apelante, pese a lo cual destacados autores consideran que la reforma no parece desacertada en este punto al entender que en dicho recurso el trámite de preparación carecía de utilidad ${ }^{15}$. Con la finalidad ya descrita se acorta también el término del emplazamiento ante el órgano ad quem, que pasa de treinta días a diez.

Los requisitos referidos al suprimido escrito de preparación se vinculan ahora al escrito de interposición (artículo 458.2) y la alegación de inadmisibilidad por la parte recurrida al trámite de oposición al recurso del artículo 461 (al cual remite el artículo 458.3), añadiéndose la exigencia de constancia expresa de haber satisfecho la tasa por ejercicio de potestad jurisdiccional (artículo 458.3) que se eleva a 300 euros; se contempla expresamente como nuevo concepto a incluir en las costas del proceso el referente al importe de la tasa por el ejercicio de potestad jurisdiccional ya que se trata de un gasto necesario; se subsana así el olvido de la anterior Ley. En relación al derecho a recurrir en casos especiales, la Ley 37/2011 modifica la redacción del artículo 449 de la LEC-2000.

La fundamentación de la apelación sigue manteniendo nuestra tradición jurídica, pues no está sujeta a motivos tasados, puede referirse a cuestiones procesales por infracciones producidas en la tramitación del proceso en primera instancia o en el momento de dictar sentencia. Las primeras exigen reposición o protesta en el momento procesal oportuno, como requisito para ser invocadas (artículo 459, LEC-2000). También puede referirse a cuestiones de fondo tanto las atinentes a las discrepancias con la valoración de los hechos recogida en la sentencia como a su fundamentación jurídica; así como a la petición de prueba (véase el artículo 460); siendo necesario citar las normas procesales que se consideren infringidas e invocar indefensión si motivadamente se estima que ésta se ha producido.

Se mantiene el tradicional trámite de admisión del recurso ${ }^{16}$, residenciado en el órgano a quo y la posibilidad de recurrir en queja frente a la inadmisión. Su ámbito objetivo debe limitarse al examen

15 Vid. Salas Carceller, en Actualidad Jurídica Aranzadi, núm. 830/2011, BIB 2011/1794.

16 El trámite de admisión ya estaba previsto en la LEC-1881, artículo 386. 
de los requisitos formales del recurso. Según la decisión que se adopte caben dos caminos posibles: admisión del recurso si el escrito reúne todos los requisitos, lo que se lleva a cabo mediante diligencia de ordenación del Secretario judicial teniendo por interpuesto el recurso y confiriendo traslado a las otras partes emplazándoles por diez días para que presenten escrito de oposición al recurso o, en su caso, de impugnación de la resolución apelada si le fuera desfavorable (artículo 461). Contra la resolución por la que se tenga por interpuesto el recurso de apelación no cabe recurso alguno (artículo 458.3) pero la parte recurrida podrá alegar las causas de inadmisibilidad en el trámite de oposición al recurso a que se refiere el artículo 461.

Para el caso de que el Secretario judicial considere que no concurren los requisitos exigidos, lo pondrá en conocimiento del tribunal para que se pronuncie sobre la admisión del recurso que, de considerar que sí concurren, dictará providencia teniéndolo por interpuesto o, en caso contrario, auto de inadmisión, contra el cual cabe interponer recurso de queja, conforme al artículo 458, anterior artículo 457.4.

En relación a las irregularidades formales del escrito de interposición, el TC sostiene que no toda irregularidad formal tiene entidad suficiente para convertirse en un obstáculo insalvable que impida la admisión del recurso ${ }^{17}$, considerando que la inadmisión del recurso solamente podrá ser constitucionalmente válida si se ampara fundadamente en causa legal y observa la debida proporción entre el defecto observado y la consecuencia asociada y que el órgano judicial no debe rechazar a limine el examen de su pretensión por defectos formales o deficiencias técnicas cuando el escrito correspondiente suministra datos suficientes para conocer, precisa y realmente, la argumentación de la parte, pues en tal caso la inadmisión puede vulnerar el artículo 24.1. CE.; la decisión errónea o arbitraria por prescindir el juzgador de los datos obrantes en dicho escrito también es contraria al precepto cita$\mathrm{do}^{18}$. En definitiva, el TC aboga por interpretar los requisitos formales que la ley establece de la forma más favorable a la admisión del recurso (SSTC 95/1985, 178/1987, 199/1994, entre otras muchas).

Conforme al artículo 463, si el apelante no comparece en el plazo de diez días ante el órgano ad quem quedará desierto el recurso y firme la resolución recurrida.

17 Vid. STC 29/1985, de 4 de julio.

18 Véase la STC 135/1998, referida al recurso de suplicación de la LPL, orden jurisdiccional social. 
Respecto a la aplicación del nuevo régimen de los recursos, la Disposición Transitoria Única establece que «los procesos que estuvieren en trámite en cualquiera de sus instancias a la entrada en vigor de la ley, continuarán sustanciándose hasta que recaiga sentencia en dicha instancia conforme a la legislación procesal anterior». A este respecto cabe recordar el ATS de 13 de marzo de 2003 sobre la aplicación del nuevo régimen a los procesos ya iniciados, en el sentido de que si la sentencia no se ha notificado antes de la entrada en vigor de la nueva Ley el régimen de recursos se regirá por ésta.

Por último, la modificación de la Ley de Enjuiciamiento Civil que se viene comentando perdió una nueva oportunidad de aclarar algunas cuestiones que, en aplicación de las diversas redacciones de la misma desde el año 2000, se vienen planteando por los órganos judiciales, especialmente por las AA.PP., en este sentido, cabe ahora hacer referencia a dos de las dudas planteadas:

A) La primera de ellas es la derivada de la redacción dada al número 1 del artículo 463 de la LEC-2000, mediante la Ley 13/2009, que establece, al referirse a la sustanciación del recurso de apelación y más concretamente, a la remisión de los autos al tribunal ad quem, que: «interpuestos los recursos de apelación y presentados, en su caso, los escritos de oposición o impugnación, el Secretario judicial ordenará la remisión de los autos al tribunal competente para resolver la apelación, con emplazamiento de las partes por término de diez días. Si el apelante no compareciere dentro del plazo señalado, el Secretario judicial declarará desierto el recurso de apelación y quedará firme la resolución recurrida». Guarda silencio el precepto sobre la imposición de costas en el supuesto contemplado, declaración de deserción del recurso. Si dicha consecuencia -el decaimiento de la apelación- se sanciona ya legalmente (pues con anterioridad, aunque nada decía la ley adjetiva, los Tribunales - no unánimemente- anudaban dicho efecto a la incomparecencia) nada se dice ahora sobre si procede o no, en tal caso, la imposición al apelante no comparecido o comparecido fuera de plazo, de las costas causadas a la contraparte. Un sector jurisprudencial considera que no es posible la imposición de costas en este supuesto, pues el Secretario judicial no está habilitado para imponerlas ya que la ley no lo establece expresamente, (como sí hace en el caso de tener por enervada la acción en el desahucio por falta de pago, o en el supuesto previsto en el artículo 458.2 del LEC). En sentido contrario, se considera mayoritariamente la necesaria imposición de costas al apelante cuyo recurso se ha declarado desierto, del mismo modo que en la LEC-1881 la fal- 
ta de personación del apelante dentro del término del emplazamiento tenía como consecuencia la exigencia de las costas a que se hubiera dado lugar, según se establecía para el juicio declarativo ordinario de mayor cuantía en el artículo $842^{19}$, incluso las ocasionadas por la simple remisión de los autos, según disponía el artículo 711 para el juicio declarativo de menor cuantía, proceso tipo en la última etapa de la Ley. De manera que también resulta tradicional en nuestro ordenamiento procesal la imposición de costas al apelante que no se persona dentro del término del emplazamiento. Conforme a la LEC-2000, en la sustanciación que se desarrolla ante el juez a quo (artículo $458.2^{\circ}$ en la redacción dada por la Ley 13/2009, de 3 de noviembre), si el apelante no presentare el escrito de interposición dentro de plazo el Secretario judicial declarará desierto el recurso de apelación y quedará firme la resolución recurrida, prescribiendo la redacción original que «la resolución que declare desierta la apelación impondrá al apelante las costas causadas, si las hubiere». Por lo tanto, parece existir una clara identidad de razón legal para adoptar ahora la misma solución ante la falta de personación del apelante e imponerle las costas del recurso, pese al silencio de la ley.

B) La segunda de las cuestiones no resueltas, es la derivada de las consecuencias que han de extraerse del supuesto de incomparecencia ante el tribunal ad quem de la parte apelada. Para un número, quizás mayoritario, de Audiencias Provinciales, la consecuencia es simplemente que no se le tiene por parte en la apelación hasta que la personación se produzca, si es que se produce, y sin retroacción del procedimiento, pues ninguna otra consecuencia se prevé legalmente. Para otro, la principal consecuencia que ha de anudarse a la no personación en plazo del apelado es la pérdida del eventual derecho a percibir las costas del recurso para el supuesto de que sea desestimado, por ejemplo, las del escrito de impugnación en la fase ante el órgano a quo.

Es lo cierto que, como se ha señalado, el recurrente tiene la obligación de personarse en tiempo y forma ante el tribunal ad quem, del que precisamente solicita la tutela, siendo la deserción el efecto explícito en caso de no verificarlo en plazo, al tratarse de recurso devolutivo, por lo que emplazada la parte y por cuanto el emplazamiento es un acto procesal de comunicación dirigido a la parte "para personarse y para actuar dentro de un plazo», cuando la personación no se produzca en tiempo oportuno, es decir, extemporáneamente ${ }^{20}$, pro-

19 «En todos los casos en que se declare desierto el recurso, se condenará en costas del mismo al apelante». 
cederá declarar desierto el recurso de apelación. El principio de igualdad de partes en el proceso supone que las cargas que respectivamente les corresponden si no se cumplen les afecten conforme a su sentido. La carga de la personación supone para el apelante que la incumple que se tenga por desierto el recurso, y la pérdida de las expectativas y derechos que pudieran derivarse de la segunda instancia, toda vez que, al faltar el presupuesto de la personación, su escrito de interposición del recurso no puede ser valorado y tenido en cuenta por el tribunal superior. La parte apelada, con su no personación, incumple el emplazamiento efectuado e igualmente hace decaer cualquier pretensión que pudiera hacer valer en la segunda instancia.

Piénsese ahora en la hipótesis de que emplazadas la parte apelante y la apelada, ninguna de ellas se persona ante la Audiencia, supuesto del que resultaría para la parte apelante la sanción de declarar desierto el recurso con imposición de las costas de la apelación; y que la parte apelada, que tampoco se había personado en tiempo y forma, al conocer tal resolución se personara posteriormente y vista la condena en costas solicitase la tasación y devengo a su favor. El desequilibrio que se produciría en este caso entre las partes es evidente, por cuanto ambas no cumplieron el presupuesto procesal de la personación, sancionándose a una de ellas con la pérdida del derecho a que su recurso sea estudiado por el tribunal ad quem mientras que, a la otra parte, se le premiaría con la percepción del importe de las costas de la apelación. Evidentemente, tal situación discriminatoria debe rechazarse de plano, como se ha dicho, y ello en atención al principio constitucional de «igualdad en la aplicación de la ley procesal» (artículo $14 \mathrm{CE}$ ), del que resulta la igualdad de partes, y supone que cada litigante goza de una posición equivalente en el plano procesal. Consiguientemente, las cargas procesales se ejercen o levantan mediante los oportunos actos procesales que debe realizar la parte afectada para evitar una desventaja procesal; así la personación es el acto procesal que cumple con la exigencia de legitimación de la parte para la actividad procesal concreta, por lo que la falta de aquélla implica la pérdida de las expectativas que de tal actividad se derivarían. Consecuentemente, con independencia de que la parte apelante haya sido condenada en costas, bien por desestimarse el recurso o porque haya sido declarado desierto, si la parte apelada no había cumplido el emplazamiento ordenado y no se personó en plazo ante el tribunal de apelación, no puede pretender el cobro de las costas de la segunda instancia. De otra parte, en la hipótesis de la per-

20 Véase el artículo 463.1 LEC. 
sonación posterior, el principio de preclusión impone la carga de aprovechar las oportunidades procesales en el término que tienen señalado para su producción (artículo 136 LEC). Argumentos todos ellos que abonan la señalada postura de impedir la posibilidad de que el apelado no comparecido sea beneficiario de condena en costas a su favor y a cargo del apelante que ha visto desestimado o declarado desierto su recurso.

\section{CONCLUSIONES}

La reforma operada en la LEC-2000 por la Ley 37/2011, de 10 de octubre, de Medidas de Agilización Procesal, afecta a los órdenes jurisdiccionales civil, penal y contencioso-administrativo. El trabajo presentado se limita exclusivamente a analizar la incidencia de la reforma en la hasta ahora vigente configuración del recurso de apelación civil, que se ve afectada por la nueva regulación que incide considerablemente en la LEC-2000 tanto en su parte general como en la especial. La reforma afecta, en cuanto al recurso de apelación, a las resoluciones recurribles y al procedimiento. Se limita el acceso del justiciable al segundo grado jurisdiccional y se suprimen trámites que el legislador considera innecesarios. La supresión del trámite de preparación conlleva que determinados requisitos vinculados al mismo se trasladan ahora al escrito de interposición, como la cita de la resolución apelada y de los pronunciamientos que se impugnan, así como la fundamentación; o la posposición de la alegación de inadmisibilidad por la parte recurrida al trámite de oposición al recurso; al tiempo que se añade la expresa mención de la necesidad de constatar el pago de la tasa por el ejercicio de potestad jurisdiccional, o de estar exento de su pago el recurrente, la cual aumenta a 300 euros.

La justificación realizada por el legislador para llevar a cabo la implantación de las denominadas «medidas de agilización procesal» se concentra en un presunto y, al parecer, generalizado uso abusivo de la segunda instancia, lo que ha sido objeto de crítica por parte de la doctrina científica considerando, un sector de la misma, que el derecho a los recursos debe encuadrarse en el derecho constitucional a un proceso con todas las garantías, no en el derecho a la tutela judicial efectiva, y que la imposibilidad de recurrir en apelación para determinados asuntos podría vulnerar el principio de igualdad consagrado en la CE. En el trasfondo de la disquisición se encuentra la doctrina del TC según la cual no existe un derecho constitucional a disponer de medios de impugnación, salvo en los procesos penales, conside- 
rando posible incluso que puedan no existir pues ninguna norma o principio constitucional impone la necesidad de una doble instancia o de unos determinados recursos, lo cual corresponde establecer al legislador en el ámbito de su libertad de creación normativa según lo considera el TC en el fundamento quinto de la STC 37/1998. 